УДК 327.5

DOI 10.18413/2687-0967-2020-47-1-218-225

\title{
ОЦЕНКА ВОЗМОЖНОСТИ РЕГИОНАЛЬНОГО ЛИДЕРСТВА МЕКСИКИ В ЛАТИНСКОЙ АМЕРИКЕ
}

\section{ASSESSMENT OF REGIONAL LEADERSHIP POTENTIAL OF MEXICO IN LATIN AMERICA}

\author{
Д.А. Тарасова, К.В. Богданов \\ D.A. Tarasova, K.V. Bogdanov
}

\author{
Национальный исследовательский Нижегородский государственный университет \\ им. Н.И. Лобачевского, \\ 603950, г. Нижний Новгород, пр. Гагарина, 23 \\ Lobachevsky State University of Nizhny Novgorod - National Research University, \\ 23 Gagarin Av., Nizhny Novgorod, 603950 Russia \\ E-mail: daria.tarasovaZ@yandex.ru; kiril1160611@yandex.ru
}

\begin{abstract}
Аннотация
В статье проводится оценка перспектив возможности становления Мексики региональным лидером в Латинской Америке. В ходе исследования авторы основываются на системном подходе, который способствует более комплексному анализу обозначенной проблемы. Для достижения поставленной цели авторы приводят определение регионального лидера и обозначают непосредственный регион. Данное исследование базируется на анализе внешней политики Мексиканских Соединенных Штатов по отношению к Латинской Америке, и тех факторов, которые влияют на ее реализацию. В этом контексте подвергается оценке роль Соединенных Штатов Америки в формировании внешней политики Мексики. Авторами выявлены основные тенденции современной политической ситуации в латиноамериканском регионе. Основываясь на приведенных в статье фактах и проведенном анализе, авторы дают оценку возможности становления Мексики региональным лидером Латинской Америки.
\end{abstract}

\begin{abstract}
The article assesses the prospects of Mexico to become a regional leader in Latin America. In the course of the research, the authors base on a systematic approach that contributes to a more comprehensive analysis of the identified problem. To achieve this goal, the authors provide a definition of a regional leader and indicate the immediate region. This study is based on the analysis of the foreign policy of the United Mexican States in relation to Latin America, and the factors that affect its implementation. Particularly the authors examine the importance of Mexico in regional integration associations and forums. In this context, the authors evaluate the role of the United States of America in the formation of the foreign policy of Mexico. The authors identify the significant trends in the current political situation in the Latin American region. Based on the facts and analysis presented in the article, the authors assess the possibilities for Mexico to achieve the regional leadership in Latin America.
\end{abstract}

Ключевые слова: регион, Латинская Америка, Мексика, региональное лидерство, Бразилия, внешняя политика.

Key words: region, Latin America, Mexico, regional leadership, Brazil, foreign policy.

Южная Америка - это регион, получивший свою известность благодаря своему открытию в 1492 г. Христофором Колумбом. Это событие дало старт испанским экспедициям на материк, которые повлекли за собой его колонизацию. Распространение испанского и португальского языков, которые принадлежат к романской группе языков, а соответственно, 
произошли от латинского языка, а также культуры Испании и Португалии дало название региону от Мексики до Аргентины, включая испаноязычные страны Карибского бассейна.

Одним из глобальных процессов, происходящих в условиях современного мира, является макрорегиональное деление мирового пространства. Латиноамериканский регион имеет длительную историю своего существования: от колониального прошлого до заметного укрепления влияния на мировой арене. В данном контексте справедливо говорить и об образовании региональных лидеров.

Сам феномен лидерства может трактоваться по-разному. Наиболее полное определение государству-лидеру дает известный российский политолог А.Д. Богатуров: «Под «типичным» лидером понимается государство, обнаруживающее объективную способность и выраженную волю, во-первых, навязать свое видение перспективы международного развития, оптимальных способов обеспечения мира и стабильности другим странам, сообществу государств в целом или какой-то его части; во-вторых, противостоять аналогичным устремлениям других лидеров или игнорировать их, не подрывая при этом основы собственной выживаемости в политическом и страновом качестве» [Богатуров,1997].

Географическое положение Мексиканских Соединенных Штатов обуславливает многие внешнеполитические процессы государства. Речь в первую очередь идет о их ближайшем северном соседе - США, протяженность границы с которыми составляет 3,2 тыс. км [Russia Today, 2018]. С конца 1980-х гг. правительство Мигеля де ла Мадрида стало сосредотачиваться на интенсификации отношений с США. Период его президентства характеризуется общим истощением мексиканской экономики, долговым кризисом и падением цен на нефть. Все эти факторы побуждали мексиканское руководство к поиску выхода из кризиса через создание зоны свободной торговли вместе с США и Канадой. Вступление в силу договора о создании североамериканской зоны свободной торговли (North American Free Trade Agreement, NAFTA) в 1994 г. на долгие годы сосредоточило внимание Мексики на североамериканском векторе внешнеполитического взаимодействия, но и оставило южноамериканские страны вне интересов Мексики, сделав восстановление мексиканского лидерства в регионе трудно исполнимым.

Однако, в 1991 г. Мексика подписала договор об экономическом сотрудничестве с Чили. Еще более значимым шагом в латиноамериканском направлении становится создание Группы трех (Grupo de los Tres, G3). Соглашение от 13 июня 1994 г., подписанное в колумбийской Картахене-де-Индиас лидерами Мексики, Колумбии и Венесуэлы, предусматривает десятипроцентное снижение тарифов на торговлю товарами и услугами между его участниками в течение десяти лет. Оно также включает такие вопросы, как инвестиции, услуги, государственные закупки, регулирование борьбы с недобросовестной конкуренцией и права интеллектуальной собственности [Tratado de Libre Comercio Colombia-México].

Спустя практически месяц там же подписывается соглашение о создании Ассоциации карибских государств между 25 странами Карибского региона, одной из странинициаторов этого процесса стала как раз Мексика. Организация призвана поощрять регионализм среди государств-членов. Основные цели ассоциации заключаются в консолидации общих интересов карибских государств и в совместной работе по устранению барьеров, оставшихся от колониального прошлого [The Convention, 1994].

Создание этих интеграционных объединений подтверждает тот факт, что Мексика все же не хотела окончательно разрывать связи со странами латиноамериканского региона. Хотя учреждающиеся институты не несли сильной политической и экономической власти, оставаясь во многих аспектах исключительно на бумаге.

B контексте NAFTA необходимо подчеркнуть, что стоимостный объѐм национального экспорта Мексиканских Соединенных Штатов увеличился более чем в 4 раза в результате роста продаж в Северную Америку, причѐм самые крупные продажи наблюдались в 1992-1995 гг. [Костюнина, 2015] Отсюда понятно, что объем экспорта страны в государства вне NAFTA составлял только лишь 4\% [Косевич, 2018]. 
По успешному же примеру NAFTA США стали активно продвигать идею создания Всеамериканской зоны свободной торговли (Acuerdo de Libre Comercio de las Américas, ALCA), и в тот момент содействие Мексики в этом вопросе было крайне необходимо. Данная идея была резко негативно воспринята странами Латинской Америки. Из-за большого количества противоречий и проблем соглашение подписано так и не было, и после этого государства Южной Америки стали искать свои пути развития. Ведущие государства региона, такие как Аргентина, Бразилия и Венесуэла, сконцентрировали свое внимание на латиноамериканской интеграции, основываясь на расширении МЕРКОСУР (Mercado Común del Sur, Mercosur) и внешнеполитической ориентации на Европейский союз и страны Азии, в частности, Китай. Мексика, Перу и Чили стали ориентироваться на многостороннее сотрудничество в рамках АТЭС [Яковлев, 2007]. Более того, из-за политики продвижения ALCA Президент Мексики В. Фокс нажил себе врагов в лице тогдашних лидеров Боливии и Венесуэлы, Э. Моралеса и У. Чавеса соответственно.

Несмотря на весьма активную внешнеполитическую деятельность В. Фокса по отношению к странам Латинской Америки, положение Мексики в этом регионе не только не укрепилось, но и заметно снизилось, и по большому счету она не имела там большого политического веса.

В ноябре 2005 г. во время Саммита Америк, проходившего в аргентинском Мар дель Плата, Мексика оказалась в центре целого ряда скандалов, произошедших на высшем уровне. Главы латиноамериканских стран высказались о том, что Мексика прямо подчиняется США. Так, в знак своего рода протеста Венесуэла вышла из Группы трех, что поставило точку в истории этого объединения. Таким образом, приблизившись к внешнеполитическому курсу США, Мексика разошлась по целому спектру вопросов с южными партнерами. Мексика стала государством, который поддерживает сценарий континентальной интеграции, предложенный США. [Проценко, 2007].

Пришедший к власти в 2006 г., Фелипе Кальдерон начал активный поворот внешнеполитического курса в страны Латинской Америки. В «Национальном плане развития Мексики 2007-2012 гг.», основном документе, определявшем внешнюю политику страны во время правления Ф. Кальдерона, Мексика позиционировала себя как страна, которая создала зрелые и справедливые отношения с Северной Америкой, и занимает лидирующие позиции в Латинской Америке [Plan Nacional de Desarroll, 2007] В этом же документе отмечалось, что одной из ключевых задач Мексики на внешнеполитическом уровне было повышение уровня страны на международной арене. Как стратегическое решение было предложено укреплять и расширять политические, экономические и культурные связи с Латинской Америкой и странами Карибского бассейна [Plan Nacional de Desarroll, 2007].

«Латиноамериканский поворот» также связан и с мировым кризисом 2008 г., который заметно ударил по экономике США и, как следствие, по мексиканской [Тарасова, 2018]. Разразившийся кризис открыл глаза мексиканскому руководству на зависимость от США, которую обеспечила им NAFTA, и заставил задуматься о переориентации внешней политики на латиноамериканский регион.

В подтверждение этого практически сразу после его подписания Мексика заключила с Аргентиной договор о стратегическом партнерстве. Позднее Ф. Кальдерон заявил о необходимости расширения связей с Бразилией, которая, в свою очередь, предложила наладить Мексике более тесное сотрудничество с Mercosur. Более того, в то же время Мексика выразила желание вступить в УНАСУР (Uniñn de Naciones Suramericanas, UNASUR) на правах наблюдателя или даже, возможно, члена, для этого был подписан «Стратегический план сотрудничества» с Уругваем и ряд экономических соглашений с другими странами региона.

В 2012 г. Мексика председательствовала на саммите G-20, проходившем в ЛосКабос, где подтвердила желание всего латиноамериканского региона занимать уверенную позицию в обсуждении насущных проблем, стоящих перед мировым сообществом, активно участвовать в создании эффективной многосторонней торговой системы [Яковлев, 2013]. 
Необходимо также отметить, что на протяжении последних десяти лет мексиканские транснациональные латиноамериканские компании успешно инвестировали в такие государства региона, как Бразилия, Чили и Колумбия.

Президент Мексики в 2012-2018 гг. Э.П. Ньето также придерживается курса на восстановление влияния Мексики в регионе. 29 января 2014 г. президент Мексики встретился с президентом Кубы Раулем Кастро в Гаване, что дало толчок к укреплению исторических отношений с Кубой в контексте всего латиноамериканского региона. Р. Кастро отметил особым приоритетом встречу с Э. Пеньей Ньето на II Саммите СЕЛАК (Comunidad de Estados Latinoamericanos y Caribeðos, CELAC) [Excelsior, 2014].

Особое внимание представляется необходимым уделить созданию в 2012 г. Тихоокеанского альянса, куда вошли Мексика, Колумбия, Перу и Чили. Ключевой функциональной особенностью данного объединения как раз и является четкая направленность стран-участников на развитие и укрепление отношений именно с конкретным регионом мира. Хотя страны альянса приветствуют развитие партнерских отношений, приоритет они отдают странам АТР. Согласно Декларации о создании Тихоокеанского альянса, подписанной в Лиме, страны-участники будут стремиться к углублению интеграции, дабы сделать себя привлекательными для инвестиций, особенно в Азиатско-Тихоокеанском регионе [Declaraciñn de Lima].

Появление новой интеграционной единицы вызвало при этом неоднозначную реакцию у ряда лидеров латиноамериканских стран. Так, например, в интервью новостному агентству Russia Today Президент Боливии Эво Моралес обвинил США в попытке разделить UNASUR посредством Тихоокеанского альянса, чтобы препятствовать расширению Боливарианского альянса для народов нашей Америки [Russia Today, 2017].

В период своего первого президентства Барак Обама выдвигал идею создания двух «стратегических» колец - тихоокеанского и трансатлантического. Разыгрывая подобную карту, США делали ставку на создание Тихоокеанского альянса, дабы сплотить главных стратегических партнеров Вашингтона в Южной Америке вокруг Вашингтона. Альянс не остался незамеченным не только в рамках региона, но и во всем мире. Об этом можно судить по числу наблюдателей. Так, на конец 2013 г. в Тихоокеанском альянсе их было 9, на начало 2015 г. - 32, а на апрель 2017 г. - уже 49 (среди которых 9 - из Азии и 20 - из Европы) [Российский совет по международным делам, 2018].

Тихоокеанский альянс также заслуживает рассмотрения с точки зрения его отношений с Mercosur, дабы проследить отношения двух лидеров данных интеграционных единиц - Бразилии и Мексики в контексте их борьбы за региональное лидерство.

Исторически Mercosur фигурировал во внешнеполитическом дискурсе Мексики практически с момента его образования. Однако своѐ предпочтение Мексика всегда отдавала США. Подписание NAFTA в 1992 г. свело на нет все попытки Мексики установить взаимовыгодные отношения со странами Mercosur, поскольку они не нуждались в партнерстве с Мексикой.

Однако в июле 2002 г. подписывается знаковое Соглашение об экономической дополняемости между Мексикой и странами-членами Mercosur. B рамках этого документа предполагалось снижение таможенных пошлин на более чем 800 продуктов и содействие созданию зоны свободной торговли между Мексикой и Бразилией [El País, 2017]. C 2007 по 2012 г. в рамках Соглашения между Бразилией и Мексикой были устранены ввозные таможенные пошлины на автомобили, но переговоры по созданию зоны свободной торговли не увенчались успехом. Это во многом связано с тем, что Бразилия все равно рассматривается элитами как конкурент, а не как партнер. Этому находится логическое объяснение. Сочетание таких факторов, как экономические реформы и относительная политическая стабильность наряду с обширной территорией и достаточно богатыми землями, придает Бразилии большой политический вес и авторитет [Рыжов, 2018].

В начале второго десятилетия XXI в. большинство стран Mercosur были во власти экономического и политического кризиса, Бразилия не стала исключением [Матвеева, 
Рыжов, 2017]. Именно в это же время появляется Тихоокеанский альянс с очевидным лидером в лице Мексиканских Соединенных Штатов. Все это сыграло на руку Мексики в отношении ее укреплений позиций в латиноамериканском регионе. Несмотря на это в 2014 г. Президент Чили Мишель Бачелет, придя к власти, поставила цель укрепить латиноамериканское единство и на саммите Тихоокеанского альянса в июне 2014 г. впервые поставила вопрос об объединении двух союзов [La Segunda, 2014]. А уже весной 2017 г. на повестке первой встречи министров иностранных дел двух объединений стоял вопрос о возможном сближении между ними [Костюнина, 2018]. Однако на данный момент о скором объединении говорить не приходится.

Большое количество созданных в Латинской Америке интеграционных объединений связано с отсутствием явного регионального лидера и определенной разобщенности стран. Это особенно четко проявилось во времена «левого поворота» в регионе, когда страны интегрировались, основываясь на идеологических убеждениях [Onuki, 2016]. Мексика и Бразилия выбрали свои пути развития, а могли бы сыграть объединяющую роль в интеграционных процессах Латинской Америки.

Особо необходимо отметить деятельность Мексики, Бразилии и Аргентины в формате G20. Деятельность этих стран в рамках этой платформы демонстрирует свою несогласованность, что свидетельствует о том, что эти государства выражают свою личную позицию, а не представляют интересы континента.

Рубеж 2018-2019 гг. ознаменовал начало эпохи перемен в латиноамериканском регионе. Это связано с приходом к власти в ведущих странах региона «нетипичных» лидеров. В Мексике на выборах впервые уверенно победил кандидат от левой коалиции «Вместе сделаем историю» (Juntos Haremos Historia) Андрес Мануэль Лопес Обрадор. В Бразилии же с 1 января 2019 г. в должность президента вступил Жаир Болсонару, являющийся лидером Социал-либеральной партии Бразилии (El Partido Social Liberal). Еще до его вступления на пост он уже пообещал беззаветно следовать политике Трампа, заикнулся о переносе бразильского посольства в Израиле в Иерусалим, о выходе из Парижского соглашения, а также выступил с жесткой критикой Mercosur [Clarín, 2018]. Эти события создали неопределенную политическую конфигурацию в регионе. Более того, исходя из риторики Президента Бразилии, можно сделать вывод о том, что страна будет сводить к минимуму свою деятельность в многосторонних форматах, переходя на двусторонние соглашения.

В этом контексте внешняя политика мексиканского Президента А.М. Лопеса Обрадора пока не вносит ясности в политическую картину в регионе. С одной стороны, во время предвыборной риторики он заявлял, что необходимо возвращаться к принципам невмешательства и самоопределения народов [Telesur, 2018.]. С другой же стороны, он не раз отмечал, что «лучшая внешняя политика - это политика внутренняя», подчеркивая, что только лишь разобравшись с внутренними проблемами в стране, можно добиться уважения своего северного соседа в лице США [Azteca Noticias, 2018]. Камнем преткновения в мексикано-американских отношениях служит проблема миграции, которую пока в Мексике не стремятся решать. С географической точки зрения Мексика также удобна и для мигрантов из Центральной Америки. Это и подтверждается мнением профессора международных отношений Университета Южной Калифорнии Сетта Стоуддера: «Мексика превратилась из страны-источника для нелегальной иммиграции в Соединенные Штаты в транзитную страну. Сейчас более половины мигрантов прибывают не из Мексики, а из Центральной Америки». [Chapman, 2017] Подобные препятствия в двусторонних отношениях могут привести к активизации внешней политики Мексики в отношении латиноамериканского региона. Одним из проявлений может служить тот факт, что в рамках Группы Лимы Мексика наряду с Кубой отказалась подписать документ о непризнании Н. Мадуро в качестве Президента Венесуэлы.

Таким образом, оценивая возможность регионального лидерства Мексики, можно сделать вывод о том, что для стран Южной Америки Мексика - это проводник Вашингтона. Ряд попыток установления взаимовыгодного сотрудничества не приносили должного 
результата. Мексиканская внешняя политика долгие годы требовала определенной корректировки, чтобы сделать перспективу становления региональным лидером более осуществимой. На протяжении последних 25 лет внешнеполитический курс Мексики характеризуется традиционно зависимым от США, что не кажется удивительным, поскольку в конце 1980-х гг. правительство Мексики сделало выбор в пользу США, тем самым «повернув» страну прочь от южноамериканских партнеров. Мексика считалось «картой» в руках Вашингтона, поскольку определѐнные инициативы, отходившие от государства, были в большей степени выгодны для США. Все это ставило под вопрос автономность региональной политики Мексиканских Соединенных Штатов, сводя на нет какую-либо возможность достичь региональное лидерство [Яковлев, 2017].

Однако тенденции, связанные с приходом к власти кандидатов с популистскими взглядами и характеризующиеся определенной «внесистемностью» свидетельствуют о начале коренных изменений в регионе, и хоть и статус регионального лидера Мексикой пока не достигнут, предпосылки к этому уже вполне очевидны.

\section{Список литературы}

1. Богатуров А.Д. 1997. Великие державы на Тихом океане. История и теория международных отношений в Восточной Азии после второй мировой войны (1945-1995). М., Конверт МОНФ, 353.

2. Косевич Е.Ю. 2018. Новые подходы Мексики к интеграционным процессам в Латинской Америке. Латинская Америка, 8: 48-62.

3. Костюнина Г.М. 2018. Интеграционные процессы в Латинской Америке как фактор содействия внешней торговле. Российский внешнеэкономический вестник, 4: 51-67.

4. Костюнина Г.М. 2015. Североамериканская интеграция: 20 лет спустя. Вестник МГИМО Университета, 2: 152-162.

5. Матвеева Д.С., Рыжов И.В. 2017. Бразилия и государство Израиль: история и современность в отношениях региональных лидеров. Вестник Московского городского педагогического университета. Серия: Исторические науки, 3 (27): 88-96.

6. Проценко А.Е. 2007. Мексикано-американские отношения в условиях глобализации. Автореф. дис. ... канд. полит. наук. М., 35 с.

7. Российский совет по международным делам. 2018. URL: http://russiancouncil.ru/analytics-and-comments/analytics/tikhookeanskiy-alyans-no-vaya-zvezda-srediintegratsionnykh-g/ (дата обращения: 01.12.2019)

8. Рыжов И.В. 2006. Проблемы регионального лидерства в современной системе международных отношений: некоторые теоретические аспекты. Вестник Нижегородского университета им. Н.И. Лобачевского. Серия: Международные отношения, Политология, Регионоведение, 2: 10-18.

9. Тарасова Д.А. 2018. Латинская Америка как арена борьбы между Китаем и Тайванем. Вестник Московского городского педагогического университета. Серия: Исторические науки, 1 (29): 65-73.

10. Яковлев П.П. 2013. «Группа двадцати»: от Мексики к России (к итогам саммита в Санкт-Петербурге) URL: http: //www.perspectivy.info/oykumena/politika/gruppa_dvad cati_ot_meksiki_k_rossii_k_itogam_sammita_v_sankt-peterburge_2013-10-08.htm.

11. Яковлев П.П. 2007. Латинская Америка: меняющийся облик. URL: http://www.perspektivy.info/oykumena/amerika/latinskaja_amerika_menajushhijsa_oblik_2007-03-19.htm

12. Яковлев П.П. 2017. «Эффект Трампа» или конец глобализации? М., РУСАЙНС, 144.

13. Azteca Noticias. 2018. LA MEJOR POLÍTICA EXTERIOR ES LA POLÍTICA INTERIOR: AMLO. URL: https://www.aztecanoticias.com.mx/la-mejor-politica-exterior-es-la-politica-interioramlo/3283922 (accessed: 26.12.2019).

14. Chapman J. 2017. The Future of U.S.-Mexico Relations is Unpredictable. URL: https://www.pacificcouncil.org/newsroom/future-us-mexico-relations-unpredictable (accessed: 28.12.2019).

15. Clarín. 2018. Brasil y México, parecidos y diferencias. URL: https://www.clarin.com/opinion/brasil-mexico-parecidos-diferencias_0_a7QJ6I5c7.html (accessed: 10.12.2019).

16. Declaraciñn de Lima. URL: https://alianzapacifico.net/documentos-acuerdo-marco-de-laalianza-del-pacifico/ (accessed: 27.12.2019). 
17. El País. 2017. Dos gigantes de espaldas. URL: https://elpais.com/internacional/2017/11/23/actualidad/1511406216_419092.html (accessed: 24.12. 2019).

18. Excelsior. México se reposiciona en relaciones exteriores. 2014. URL: http://www.excelsior.com.mx/nacional/2014/06/06/963622 (accessed: 27.12.2019).

19. La Segunda. 2014. Bachelet pide a Alianza del Pacífico acercarse al Mercosur. URL: http://www.lasegunda.com/Noticias/Politica/2014/06/943082/Bachelet-presenta-en-Cumbre-de-AlianzaPacifico-su-propuesta-de-apertura-al-Mercosur (accessed: 24.12.2019).

20. Onuki J., Mouron F., Urdinez F. Latin American Perceptions of Regional Identity and Leadership in Comparative $\quad$ Perspective. $2016 . \quad$ URL: http://www.scielo.br/scielo.php?script=sci_arttext\&pid=S0102-85292016000100433 (accessed: 26.12.2019).
21. Plan
Nacional
de Desarrollo
2007-2012. 2007.
P.128.
URL: http://www.cefp.gob.mx/intr/edocumentos/pdf/cefp/cefp0962007.pdf

22. Russia Today. 2017. «Planetu nel'zya privatizirovat'»: prezident Bolivii Evo Morales dal interv'yu RT. URL: https://russian.rt.com/world/article/383363-evo-morales-intervyu (data obrashcheniya: 21.12.2019).

23. Russia Today. 2018. I tseloy steny malo: zachem Donal'd Tramp styagivayet voyska $\mathrm{k}$ meksikanskoy granitse. URL: https://russian.rt.com/world/article/501026-meksika-stena-tramp-nelegaly (data obrashcheniya: 28.12.2019).

24. Telesur. 2018. AMLO: México aplicará política exterior de no intervenciñnURL: https://www.telesurtv.net/news/mexico-amlo-politica-exterior-marcelo-ebrard--20180705-0095.html (accessed: 26.12.2019).

25. The Convention Establishing the Association of Caribbean States. 1994. URL: $\mathrm{http} / / / \mathrm{www}$.acs-aec.org/index.php?q=about/convention-establishing-the-association-of-caribbean-states (accessed: 04.12. 2019).

26. Tratado de Libre Comercio Colombia-México. URL:

http://www.sice.oas.org/trade/go3/G3INDICE.asp (accessed 22.12.2019).

\section{References}

1. Bogaturov A.D. 1997. Velikie derzhavy na Tihom okeane. Istoriya i teoriya mezhdunarodnyh otnoshenij v Vostochnoj Azii posle vtoroj mirovoj vojny (1945-1995) [Great powers on the Pacific Ocean. History and theory of international relations in the Eastern Asia after the Second World War (1945-1995)]. Moscow, Konvert - MONF, 353.

2. Kosevich E.Y. 2018. Novye podhody Meksiki k integracionnym processam v Latinskoj Amerike [New approaches of Mexico to the integration processes in Latin America]. Latinskaya Amerika, 8: 48-62.

3. Kostyunina G.M. 2018. Integracionnye processy v Latinskoj Amerike kak faktor sodejstviya vneshnej torgovle [Integration processes in Latin America as a factor of foreign trade contribution]. Rossijskij vnesh-neekonomicheskij vestnik, 4: 51-67.

4. Kostyunina G.M. 2015. Severoamerikanskaya integraciya: 20 let spustya [North American integration: 20 years after]. Vestnik MGIMO Universiteta, 2: 152-162.

5. Matveyeva D.S., Ryzhov I.V. 2017. Braziliya i gosudarstvo Izrail': istoriya i sovremennost' v otnosheniyakh regional'nykh liderov [Brazil and Israel: history and the present in the relations of regional leaders]. Vestnik Moskovskogo gorodskogo pedagogicheskogo universiteta. Seriya: Istoricheskiye nauki, № 3 (27): 88-96.

6. Procenko A.E. 2007. Meksikano-amerikanskie otnosheniya v uslovi-yah globalizacii [Mexico-American relations in terms of globalization]. Abstract. dis. ... cand. polit. nauk. Moscow, 35 p.

7. Rossiyskiy sovet po mezhdunarodnym delam. 2018. URL: http://russiancouncil.ru/analyticsand-comments/analytics/tikhookeanskiy-alyans-no-vaya-zvezda-sredi-integratsionnykh-g/ (data obrashcheniya: 01.12.2019)

8. Ryzhov I.V. 2006. Problemy regional'nogo liderstva v sovremennoj sisteme mezhdunarodnyh otnoshenij: nekotorye teoreticheskie aspekty [Problems of regional leadership in the modern system of international relations: some theoretical aspects]. Vestnik Nizhegorodskogo universiteta im. N.I. Lobachevskogo. Seriya: Mezhdunarodnye otnosheniya, Politologiya, Regionovedenie, 2: 10-18.

9. Tarasova D.A. 2018. Latinskaya Amerika kak arena bor'by mezhdu Kitayem i Tayvanem [Latin America as an arena of confrontation between China and Taiwan]. Vestnik Moskovskogo gorodskogo pedagogicheskogo universiteta. Seriya: Istoricheskiye nauki, 1 (29); 65-73. 
10. Yakovlev P.P. 2013. «Gruppa dvadtsati»: ot Meksiki k Rossii (k itogam sammita v SanktPeterburge) [«Group 20»: from Mexico to Russia (results of the summit in Saint Petersburg]. URL: http://www.perspectivy.info/oykumena/politika/gruppa_dvadcati_ot_meksiki_k_ ii_k_itogam_sammita_v_sankt-peterburge_2013-10-08.htm

ross

11. Yakovlev P.P. 2007. Latinskaya Amerika: menyayushchiysya oblik [Latin America: changing character]. URL: http://www.perspektivy.info/oykumena/amerika/latinskaja_amerika_mena jushhijsa_oblik_2007-03-19.htm

12. Yakovlev P.P. 2017. «Effekt Trampa» ili konec globalizacii? [«Trump's effect» or the end of globalization]. Moscow, RUSAJNS, 2017, 144.

13. Azteca Noticias. 2018. LA MEJOR POLÍTICA EXTERIOR ES LA POLÍTICA INTERIOR: AMLO. URL: https://www.aztecanoticias.com.mx/la-mejor-politica-exterior-es-la-politica-interioramlo/3283922 (accessed: 26.12.2019).

14. Chapman J. 2017. The Future of U.S.-Mexico Relations is Unpredictable. URL: https://www.pacificcouncil.org/newsroom/future-us-mexico-relations-unpredictable (accessed: 28.12.2019).

15. Clarín. 2018. Brasil y México, parecidos y diferencias. URL: https://www.clarin.com/opinion/brasil-mexico-parecidos-diferencias_0_a7QJ6I5c7.html (accessed: 10.12.2019).

16. Declaraciñn de Lima. URL: https://alianzapacifico.net/documentos-acuerdo-marco-de-laalianza-del-pacifico/ (accessed: 27.12.2019).

17. El País. 2017. Dos gigantes de espaldas. URL: https://elpais.com/internacional/2017/11/23/actualidad/1511406216_419092.html (accessed: 24.12. 2019).

18. Excelsior. México se reposiciona en relaciones exteriores. 2014. URL: http://www.excelsior.com.mx/nacional/2014/06/06/963622 (accessed: 27.12.2019).

19. La Segunda. 2014. Bachelet pide a Alianza del Pacífico acercarse al Mercosur. URL: http://www.lasegunda.com/Noticias/Politica/2014/06/943082/Bachelet-presenta-en-Cumbre-de-AlianzaPacifico-su-propuesta-de-apertura-al-Mercosur (accessed: 24.12.2019).

20. Onuki J., Mouron F., Urdinez F. Latin American Perceptions of Regional Identity and Leadership in Comparative Perspective. 2016.2 URL: http://www.scielo.br/scielo.php?script=sci_arttext\&pid=S0102-85292016000100433 (accessed: 26.12.2019).

21. Plan Nacional de Desarrollo 2007-2012. 2007. P.128. URL: http://www.cefp.gob.mx/intr/edocumentos/pdf/cefp/cefp0962007.pdf

22. Russia Today. 2017. «Planetu nel'zya privatizirovat'»: prezident Bolivii Evo Morales dal interv'yu RT. URL: https://russian.rt.com/world/article/383363-evo-morales-intervyu (data obrashcheniya: 21.12.2019).

23. Russia Today. 2018. I tseloy steny malo: zachem Donal'd Tramp styagivayet voyska $\mathrm{k}$ meksikanskoy granitse. URL: https://russian.rt.com/world/article/501026-meksika-stena-tramp-nelegaly (data obrashcheniya: 28.12.2019).

24. Telesur. 2018. AMLO: México aplicará política exterior de no intervenciñnURL: https://www.telesurtv.net/news/mexico-amlo-politica-exterior-marcelo-ebrard--20180705-0095.html (accessed: 26.12.2019).

25. The Convention Establishing the Association of Caribbean States. 1994. URL: http://www.acs-aec.org/index.php?q=about/convention-establishing-the-association-of-caribbean-states (accessed: 04.12. 2019).

26. Tratado de Libre Comercio Colombia-México. URL:

http://www.sice.oas.org/trade/go3/G3INDICE.asp (accessed 22.12.2019).

\section{Ссылка для цитирования статьи Reference to article}

Тарасова Д.А., Богданов К.В. 2020. Оценка возможности регионального лидерства Мексики в Латинской Америке. Via in tempore. История. Политология, 47(1): 218-225.

DOI 10.18413/2687-0967-2020-47-1-218-225

Tarasova D.A., Bogdanov K.V. 2020. Assessment of regional leadership potential of Mexico in Latin America. Via in tempore. History and political science, 47(1): 218-225 (in Russian).

DOI 10.18413/2687-0967-2020-47-1-218-225 